\title{
Promotion of immune and glycaemic functions in streptozotocin-induced diabetic rats treated with un-denatured camel milk whey proteins
}

\author{
Hossam Ebaid ${ }^{1,2}$
}

\begin{abstract}
T cell mediated autoimmune diabetes is characterized by immune cell infiltration of pancreatic islets and destruction of insulin-producing $\beta$-cells. This study was designed to assess the effect of whey proteins (WP) on the responsiveness of lymphocytes in rats after four months of Streptozotocin (STZ)-induced Type 1 diabetes (T1D). A diabetic group was supplemented with WP daily for five weeks at a dose of $100 \mathrm{mg} / \mathrm{kg}$. Ribonucleic acid (RNA) was extracted from stimulated lymphocytes in order to analyse gene expressions using real time PCR and RT-PCR. PCR results were confirmed with ELISA. The proliferation capacity of lymphocytes and their homing to the spleen were studied. Antigen-activated lymphocytes showed that diabetes impaired the mRNA expression of the protein kinase B (Akt1), Cdc42, and the co-stimulatory molecule, CD28, which are important for cell survival, actin polymerization and $T$ cell activation, respectively. Accordingly, proliferation of lymphocytes was found to be suppressed in diabetic rats, both in vivo and in vitro. WP was found to restore Akt1, Cdc42 and CD28 mRNA expression during diabetes to normal levels. WP, therefore, served to activate the proliferation of B lymphocytes in diabetic rats both in vivo and in vitro. Although WP was found to up-regulate mRNA expression of both interleukin (IL)-2 and interferon gamma (IFN- $\gamma)$, it suppressed the proliferation activity of almost all T cell subsets. This was confirmed by WP normalizing the structure and function of $B$ cells. Meanwhile, WP was found to down regulate the mRNA expression of Tumor necrosis factor-alpha (TNF-a) and its programmed cell death-receptor (Fas). Taken together, the results of this study provide evidence for the potential impact of WP in the treatment of immune impairment in T1D, suggesting that it serves to reverse autoimmunity by suppressing autoreactive $T$ cells and down regulating TNF- $\alpha$ and Fas, resulting in improved pancreatic $B$ cell structure and function.
\end{abstract}

Keywords: Lymphocyte proliferation, T and B cells, Pancreatic B cells, Type 1 diabetes-rat model, Whey protein

\section{Introduction}

Homeostasis within the immune system needs to selectively force the survival of useful lymphocytes in the central lymphoid organs and antigen-reactive cells in the periphery, whilst deleting strongly autoreactive cells in the thymus and bone marrow [1]. CD4+ T-helper cells differentiate into three subsets of effector cells: Th1, Th2, and Th17. An overactive Th1 response can lead to autoimmune diseases such as T1D [2]. T cell activation involves multiple interactions with the cell surface,

Correspondence: hossamebaid@yahoo.com

'Department of Zoology, College of Science, King Saud University, Saudi Arabia, Riyadh, KSA

${ }^{2}$ Department of Zoology, Faculty of Science, El-Minia University, El-Minia, Egypt

\section{() Biomed Central}

including co-stimulatory molecules such as CD28, and signaling from cytokine or chemokine receptors [3]. Recent studies provide evidence that CD28 co-stimulation of different cytokines is mediated by discrete signaling pathways, one of which includes protein kinase B (Akt) [4] which is known to protect cells against apoptosis [5]. Dysregulation of Akt leads to diseases such as cancer, and diabetes as well as cardiovascular and neurological diseases [6] and schizophrenia [7]. Cdc42, a member of the Rho family of GTPases, plays a role in cell motility and migration $[8,9]$ and regulates the dynamics of the cytoskeleton [10]. Runne et al. [11] found that Cdc42 activation regulates lymphocyte chemotaxis. Guo et al. meanwhile, [12] showed that Cdc42 maintains naïve $\mathrm{T}$ cell homeostasis through promotion of cell survival and suppression of T cell activation. 
ß-cell apoptosis involves multiple signaling cascades stimulated by interleukin (IL)- $1 \beta$, interferon-gamma (IFN- $\gamma$ ), and tumor necrosis factor-alpha (TNF- $\alpha$ ) [13]. The TNF superfamily causes recruitment of several intracellular adaptors, such as Fas, to activate multiple signal transduction pathways that induce apoptosis [14]. The eventual fate of the cell is dependent on integrated signals received through the antigen receptor, co-stimulatory receptors, cytokine receptors and members of the TNF receptor family, with these signals being highly specialized to promote either the survival or death of the cell, and thus eventually to return the immune response to a state of homeostasis.

Identifying proteins that normally regulate immune response and decrease apoptosis in diabetics offers the opportunity to develop novel therapeutic strategies. Whey proteins (WP) has been postulated to reduce the effects of oxygen radicals by increasing glutathione [15-18], which stimulates lymphocyte proliferation, increases mast cells and their associated cytokines and biochemical mediators, and enhances the humoral immune response. Furthermore, a recent study has successfully determined the role of WP in restoring the normal inflammatory phase of the wound healing process in diabetic models [15] and the proliferation of PBMC [16]. WP is easily available from different milk sources, especially camels, in Saudi Arabia. The current study builds on this work by assessing whether WP can influence the outcome and progression of diabetic immune defects. Specifically, we investigated the impact of WP on $ß$ cell functions and on lymphocyte activation and proliferation in an animal model of T1D.

\section{Materials and methods}

Preparation of un-denatured camel milk whey proteins

The milk was skimmed by centrifugation at $5000 \mathrm{~g}$ for 20 min using an IEC Model $\mathrm{K}$ centrifuge [Boston, USA]. Skim milk was acidified to $\mathrm{pH} 4.3$ using $1 \mathrm{M}$ of $\mathrm{HCl}$. The precipitated casein was removed by centrifugation, and the supernatant containing the whey protein was saturated with ammonium sulfate (70\% saturation) and incubated overnight at $4^{\circ} \mathrm{C}$. The precipitated whey proteins were collected by centrifugation and dialyzed against distilled water for $48 \mathrm{~h}$ at $4^{\circ} \mathrm{C}$ using a Spectra/Pro ${ }^{\circ}$ Membrane, MWCO 6000-8000 Da. The obtained dialyzate was lyophilized using a Unitop 600 SL, [Virtis Company, Gardiner, New York 12525 USA] and were kept at $-20^{\circ} \mathrm{C}$ until use. The dialyzate containing un-denatured whey proteins were freeze-dried and refrigerated until use.

\section{Ethical approval}

Camel milk was obtained from a camel breed (Majaheem) from the Najd region (Alazeria farm; GPS: 30002 47/ 300 02 27) in Saudi Arabia. Specific permissions were not required for activities in this private farm. This study did not involve endangered or protected species. Regarding experimental animals, all procedures were conducted in accordance with the standards set forth in the guidelines for the care and use of experimental animals by the Committee for the Purpose of Control and Supervision of Experiments on Animals and the National Institutes of Health. The study protocol (care and handling of experimental animals) was approved by the Animal Ethics Committee of the Zoology Department in the College of Science at King Saud University.

\section{Diabetic models}

Diabetes was induced by a single injection of freshly dissolved STZ (60 mg/kg of body weight; Sigma, USA) in a $0.1 \mathrm{~mol} / \mathrm{l}$ citrate buffer ( $\mathrm{pH} 4.5$ ) into the peritoneum [19]. Control rats were injected with citrate buffer. Seven days after STZ injection, the rats were screened for serum glucose levels. Rats with a serum glucose level $\geq 200 \mathrm{mg} / \mathrm{dl}$ after $2 \mathrm{~h}$ of glucose intake were considered diabetic and selected for further studies.

\section{Experimental diet}

Rats were supplemented with whey protein in the diet as previously described [20-22]. To prepare $500 \mathrm{~g}$ of the diet, 5 g vitamins, $25 \mathrm{~g}$ mineral salts, $40 \mathrm{~g}$ fats, $50 \mathrm{~g}$ sucrose, $100 \mathrm{~g}$ protein (20\% protein) and $280 \mathrm{~g}$ starch were mixed. Casein was the protein source in both the control and the diabetic groups. The un-denatured camel milk whey protein was the protein source in the WP-treated diabetic group. The diet was kept at $4^{\circ} \mathrm{C}$ until use [23].

\section{Experimental design}

A total of 45 male rats (12-week-old), weighing 120$150 \mathrm{~g}$ each, were obtained from the Central Animal House of the Faculty of Pharmacy at King Saud University. All animals were allowed to acclimatize in metal cages inside a well-ventilated room for 2 weeks prior to the experiment. Animals were maintained under standard laboratory conditions (temperature at $23^{\circ} \mathrm{C}$, relative humidity was $60 \%-70 \%$ and a 12 -h light/dark cycle) and were fed a diet of standard commercial pellets and given water ad libitum. Animals were distributed into three experimental groups $(\mathrm{n}=15 /$ group$)$ : group I was daily administered $1 \%$ carboxymethyl cellulose (CMC), group II diabetic rats (DM) was supplemented with distilled water $(250 \mu \mathrm{l} / \mathrm{rat} /$ day $)$ for five weeks and group III was supplemented with camel milk un-denatured WP (DMWP) $(100 \mathrm{mg} / \mathrm{kg} /$ body weight dissolved in $250 \mu \mathrm{l} /$ day) for five weeks. Rats of the third group were freely supplemented with camel milk un-denatured whey proteins as a protein constituent of the diet. An additional supplementary group of normal rats treated with WP was studied for confirming the results of the three main groups. However, data from these groups are not included in this study. 


\section{Collection of samples}

The animals from all groups were autopsied under light ether anesthesia. At the end of the experimental period, blood was drawn from the animals by puncturing retroorbital venous sinus with capillary tubes until killing. Sera were used for the determination of glucose level. After collection of blood samples, the animals from all groups were autopsied under light ether anesthesia. Subsequently, spleen was excised from surrounding tissues and parts were placed into tubes with fixatives (10\% formalin) for histological and immunochemical studies. Other splenic parts were placed in buffers for lymphocytes isolation.

\section{Estimation of glucose and insulin concentration}

Serum glucose concentration was determined according to the Trinder method [24] using a commercial diagnostic kit (Biodiagnostics, Egypt). Serum insulin was assayed using a DPC radioimmunoassay kit (Diagnostic Products Corporation, Los Angeles, USA) [coat-A-count] according to the method reported by Marschner et al. [25].

\section{Lymphocyte isolation}

Rats were anesthetized and euthanized; spleen was taken out immediately and rinsed with cold phosphate buffered saline and then placed on a 200-mesh stain steel sieve and grounded with plunger of glass syringe. Two volume of isolated lymphocyte separation medium was added, mixed gently, and centrifuged at 2,000 $\times \mathrm{g}$ for $10 \mathrm{~min}$. The top layer was discharged leaving the middle lamella layer, showing milk cream color, contained lymphocytes. Five volume of PBS buffer was added and centrifuged at $1,000 \times \mathrm{g}$ for $5 \mathrm{~min}$. Precipitated lymphocytes were re-suspended in RPMI-1640 medium (making the final concentration of $1 \times 10^{6}$ cells/ $\mathrm{mL}$ ). The viability of lymphocytes was analyzed using trypan blue, and in all acceptable preparations, it exceeded 95\%.

\section{T and B lymphocyte proliferation assay}

The proliferation was determined in sterile flat-bottomed 96-well culture plate. Lymphocyte suspension was on the plate, then RPMI-1640 medium containing concanavalin A (Con A, making the final concentration of $5 \mathrm{mg} / \mathrm{L}$ for $\mathrm{T}$ cell or $10 \mathrm{mg} / \mathrm{L}$ lipopolysaccharide for B cells) was added and incubated at $37^{\circ} \mathrm{C}$ under $5 \% \mathrm{CO}_{2}$ for $24 \mathrm{~h}$. Then, 20 $\mu \mathrm{L}$ MTT $(5 \mathrm{~g} / \mathrm{L})$ was added to each plate and incubated for another $4 \mathrm{~h}$. The supernatants were sucked and discarded; $150 \mu \mathrm{L}$ of dimethyl sulfoxide was added to each plate and shaken. The optical absorbance at $490 \mathrm{~nm}$ was recorded in an ELISA plate reader as previously described [26,27]. There were ten replicates for each rat lymphocytes.

\section{Immunohistochemical detection of proliferated cell nuclear antigen (PCNA), $T$ and $B$ cells}

Spleen samples were fixed in 10\% neutral buffered formalin Paraffin sections were cleared in xylene, rehydrated in graded ethanol (100\%-70\%), immersed in water for 5 to 10 minutes, and incubated in $0.3 \% \mathrm{H}_{2} \mathrm{O}_{2}$ in $70 \%$ methanol for 20 minutes to inhibit endogenous peroxidase activity. The specimens were then rinsed three times for 5 minutes in PBS, and epitopes were unmasked by boiling in citrate buffer ( $\mathrm{pH}$ 6.0) for 15 minutes, when necessary. The sections then were blocked for 60 minutes in 3\% BSA in PBS or in $1 \%$ normal goat serum and $3 \%$ non-fat milk. Section were incubated with primary antibodies (Anti-PCNA [Novo Castra NCL-PCNA], anti-CD3; pan T cells or antiCD20; pan B cells) in $0.1 \%$ BSA overnight at $4^{\circ} \mathrm{C}$ in a humidified chamber. Samples were then rinsed in PBS and incubated with biotinylated secondary antibody in $0.1 \%$ BSA for 1 hour at room temperature, followed by avidin biotin amplification (ABC Elite) for 30 minutes. Sections were developed with 3,3-diaminobenzidine peroxidase substrate (Sigma). Sections were counterstained with Mayer haematoxylin for 3 minutes and mounted. Negative controls were set by substituting the primary antibody with PBS [28]. Photographs of the sections were taken; the images were digitized using Adobe Photoshop (Adobe Systems, Mountain View, CA). The PCNA (the number of brown stained cells), anti-CD3 or anti-CD20-stained cells were determined at 20 random locations within the spleen follicles and the PALS for each animal from each group using a Leica Qwin 500 image analyzer.

\section{RNA extraction and RT-PCR}

RNA was extracted from the collected samples (RNA latter) using RNeasy Mini Kit (QIAGEN) according to the manufacturer instructions. RT-PCR was performed using QIAGEN One Step RT-PCR kit as directed by the manufacturer's instruction manual. The desired genes were amplified using specific primers (e-oligos, Hawthorne, USA) listed in Table 1. For each sample, $25 \mu$ l reaction mixture was performed. PCR reaction was carried out using Gene-Amp 9700 thermal cycler. RT-PCR products were analyzed in $1.2 \%$ agarose gel. PCR conditions were optimized to allow semiquantitative comparisons of results, as previously described [29]. The levels of the three mRNA and $\beta$-actin mRNA were quantified by gel electrophoresis and densitometry. mRNA levels were normalized versus $\beta$-actin and are expressed in arbitrary units.

Quantification of mRNA expression by real-time polymerase chain reaction cDNA from the above preparation was subjected to PCR amplification using 96-well optical reaction plates in the ABI Prism 7500 System (Applied Biosystems $\left.{ }^{\circ}\right)$. The $25-\mu \mathrm{l}$ reaction mixture contained $0.1 \mu \mathrm{l}$ of $10 \mu \mathrm{M}$ forward primer and $0.1 \mu \mathrm{l}$ of $10 \mu \mathrm{M}$ reverse primer ( $40 \mu \mathrm{M}$ final concentration of each primer), $12.5 \mu \mathrm{l}$ of SYBR Green Universal Mastermix, $11.05 \mu \mathrm{l}$ of nucleasefree water, and $1.25 \mu \mathrm{l}$ of cDNA sample. The primers used in the current study were chosen from pubmed. com. The RT-PCR data was analyzed using the relative 
Table 1 List of primers used to amplify the desired genes

\begin{tabular}{|c|c|c|c|}
\hline \multirow{2}{*}{$\frac{\text { Primer name }}{\mathrm{IL}-2}$} & \multicolumn{2}{|c|}{$5^{\prime}--\ldots---<<3^{\prime}$} & \multirow{2}{*}{$\begin{array}{l}\text { Primer length } \\
20\end{array}$} \\
\hline & Forward & CCTGAGCAGGGAGAATTACA & \\
\hline & Reverse & TCCAGAACATGCCGCAGA & 18 \\
\hline \multirow[t]{2}{*}{ Fas } & Forward & GAGAATTGCTGAAGACATGACAATCC & 26 \\
\hline & Reverse & ATGGCTGGAACTGAGGTAGTIITCAC & 26 \\
\hline \multirow[t]{2}{*}{ Akt1 } & Forward & CCTITATTGGCTACAAGGAACGG & 23 \\
\hline & Reverse & GAAGGTGCGCTCAATGACTG & 20 \\
\hline \multirow[t]{2}{*}{ CD28 } & Forward & GTATTCCTACAACCTTCTCGCAA & 23 \\
\hline & Reverse & GGGGCTGATAGGTAAAATTCCCA & 23 \\
\hline \multirow[t]{2}{*}{ Cdc42 } & Forward & TTCTGGTTGTGTTTCAACTGCT & 22 \\
\hline & Reverse & CCTCCCTTGGACTGCATCTG & 20 \\
\hline \multirow[t]{2}{*}{$\operatorname{lnf}-\gamma$} & Forward & GCCCAATATCTCGGATGCTTC & 21 \\
\hline & Reverse & GCCAAAATAGCTTCGGTAATCCT & 23 \\
\hline \multirow[t]{2}{*}{ TNF-a } & Forward & CCAACATGCTGATTGATGACACC & 23 \\
\hline & Reverse & GAGAATGCCAATTITGATTGCCA & 23 \\
\hline
\end{tabular}

gene expression method, as described in Applied Biosystems ${ }^{\oplus}$ User Bulletin No. 2. The data are presented as the fold change in gene expression normalized to the endogenous reference gene and relative to a calibrator.

\section{Statistical analysis}

The statistical analysis was performed using the MINITAB software (MINITAB, State College, PA, Version 13.1, 2002). The data from the experiments were tested for normality using the Anderson Darling test, and for variance homogeneity prior to any further statistical analysis. The data were normally distributed with homogeneous variances. Thus, the one-way ANOVA statistical measure was used to determine the overall effect of each treatment. This measure was supplemented by individual comparison between the different treatments using Tukey's method for pairwise comparisons. The results were expressed as arithmetic mean $(\mathrm{M}) \pm$ standard deviation (SD). Only statistically significant differences with $\mathrm{P}<0.05$ were found between the treatment group and the control, and between the treatment group and the diabetic group considered.

\section{Results}

WP restores Akt1, Cdc42 and CD28 signaling during diabetes

To assess whether WP supplementation could influence T-cell survival, activation and proliferation in T1D, we investigated the mRNA expression of Akt1, CD28 and Cdc42. mRNA expression of the activated lymphocytes showed that diabetes impaired the Akt1 (234 \pm 9.5$)$, CD28 $(229 \pm 14)$ and Cdc42 $(33 \pm 6.5)$ signaling compared to those of the control group [Akt1 (252 \pm 12$)$, CD28 (235 \pm 10), Cdc42 (45 \pm 5.0$)]$. WP supplementation, however, was found to restore mRNA expression of Akt1 (255 \pm 16),
CD28 (240 \pm 14$)$ and Cdc42 (47 \pm 4.0$)$ close to the normal level (Figure 1a,b,c,d). Up-regulation of Akt1, Cdc42 and CD28 expression was also evident in diabetic rats supplemented with WP.

\section{WP activates lymphocyte proliferation in diabetic rats in vivo and in vitro}

To validate these observations and to determine the effect of WP on lymphocyte activities, lymphocytes from the WP-treated diabetic rats, the diabetic and the control groups were isolated and examined for cell proliferation. Viability of the lymphocytes was measured by trypan blue exclusion test. Approximately $80 \%$ lymphocytes of diabetic rats were killed in medium during 72 hours of incubation comparing to the control rats (Figure 2a). Non-significant changes of the lymphocytes derived from WP-treated diabetic rats comparing to the control rats (Figure 2a). The mitogen stimulated (Con A or LPS) lymphocytes derived from WP-treated diabetic rats demonstrated significantly higher proliferative activity ( $90 \%$ or $110 \%$, respectively) as compared to those from the diabetic rats $(50 \%$ or $45 \%$, respectively) (Figure 2b,c).

To examine the impact of WP on lymphocyte proliferations further, spleen sections were stained with PCNA antibodies. PCNA-stained sections appeared to exhibit minimal proliferation activity in diabetic group compared to the control group (Figure 3). Lymphocytes stained with PCNA antibodies in the germinal centers of follicles from WP-treated rats showed very high proliferation activity (Figure 3). Periarteriol lymphatic sheath (PALS) cells (almost T cells) from WP-treated rats, showed a significantly higher capacity $(35 \pm 4.55)$ for proliferation than those of diabetic animals $(2.0 \pm 0.06)$ (Figure 3$)$. In spleen follicle, cells from WP-treated rats, showed more than twenty 
a mRNa expression of Akt1, Quantitative PCR

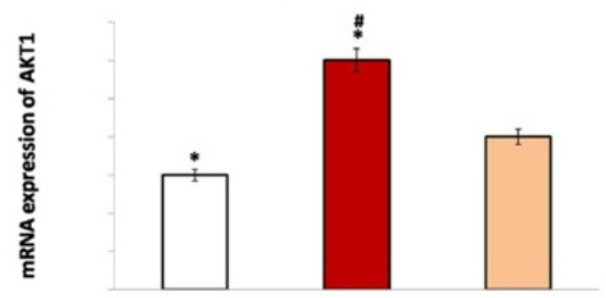

b mRNa expression of Akt1, RT-PCR

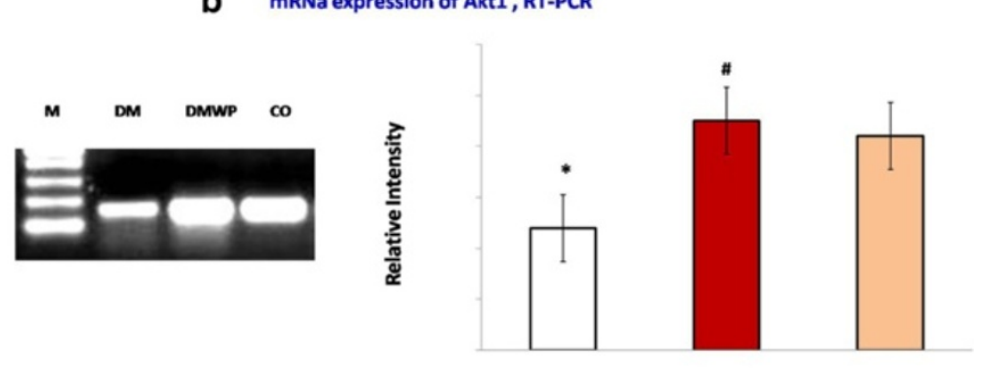

C mRNa expression of CDC-42, RT-PCR

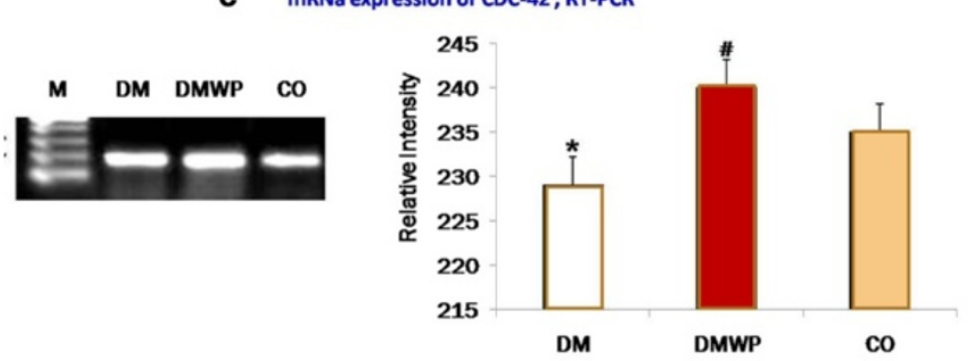

d mRNa expression of CD-28, RT-PCR

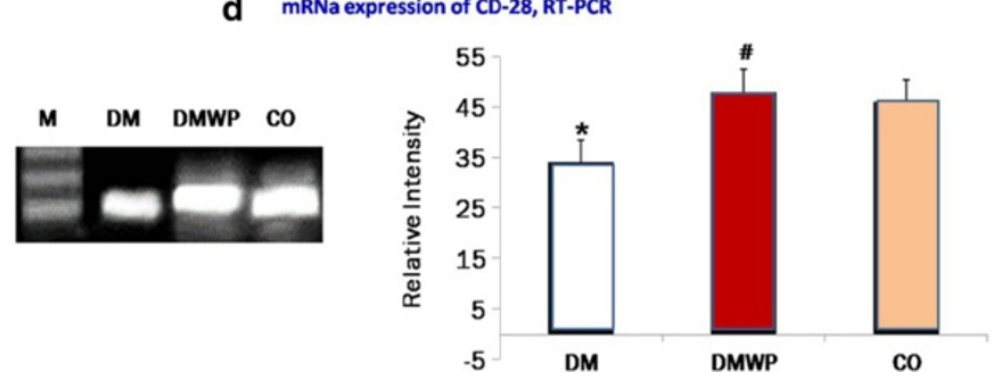

Figure 1 Quantitative analysis of mRNA expression of AKT1 genes (a). Semiquantative PCR-mRNA expression of Akt1 (b), CD28 (c) and Cdc42 (d) of the antigen activated lymphocytes from control, DM and DMWP rats. PCR products were separated and visualized by DNA agarose electrophoresis after amplification of Akt1, CD28 and Cdc42 from splenocyte genomic DNA. Samples from five animals were analyzed. A representative result from each group is presented, while the values in the histograms are the mean \pm SD. ${ }^{*}$ shows the significance $(p<0.05)$ in comparison to the control group. \#shows the significance $(p<0.05)$ in comparison to the diabetic group.

eight fold higher capacity for proliferation $(113 \pm 7.45)$ than those of diabetic animals $(4.0 \pm 0.78)$ (Figure 3$)$.

\section{WP forces survival of B lymphocytes and strongly} suppresses T cells

Following the observed mitogenic activity of WP shown previously in this work, we determined the extent to which both $\mathrm{B}$ and $\mathrm{T}$ cells were activated by this protein. Spleen sections were stained with anti-CD20 or anti-CD3 antibodies to realize B or T cells, respectively (Figure 4a-f). Figure $4 \mathrm{~g}$ shows that the number of $\mathrm{B}$ cells was significantly $(P<0.05)$ reduced in both the marginal zone and lymphatic follicles of the diabetic rats $(25 \pm 1.5)$ compared to the control group $(31 \pm 1.4)$. On the other hand, the number of $B$ cells in diabetic rats supplemented with WP were significantly $(P<0.05)$ increased $(94 \pm 4.59)$ in both the marginal zone and lymphatic follicles compared to the diabetic and the control rats, respectively (Figure 4g). 


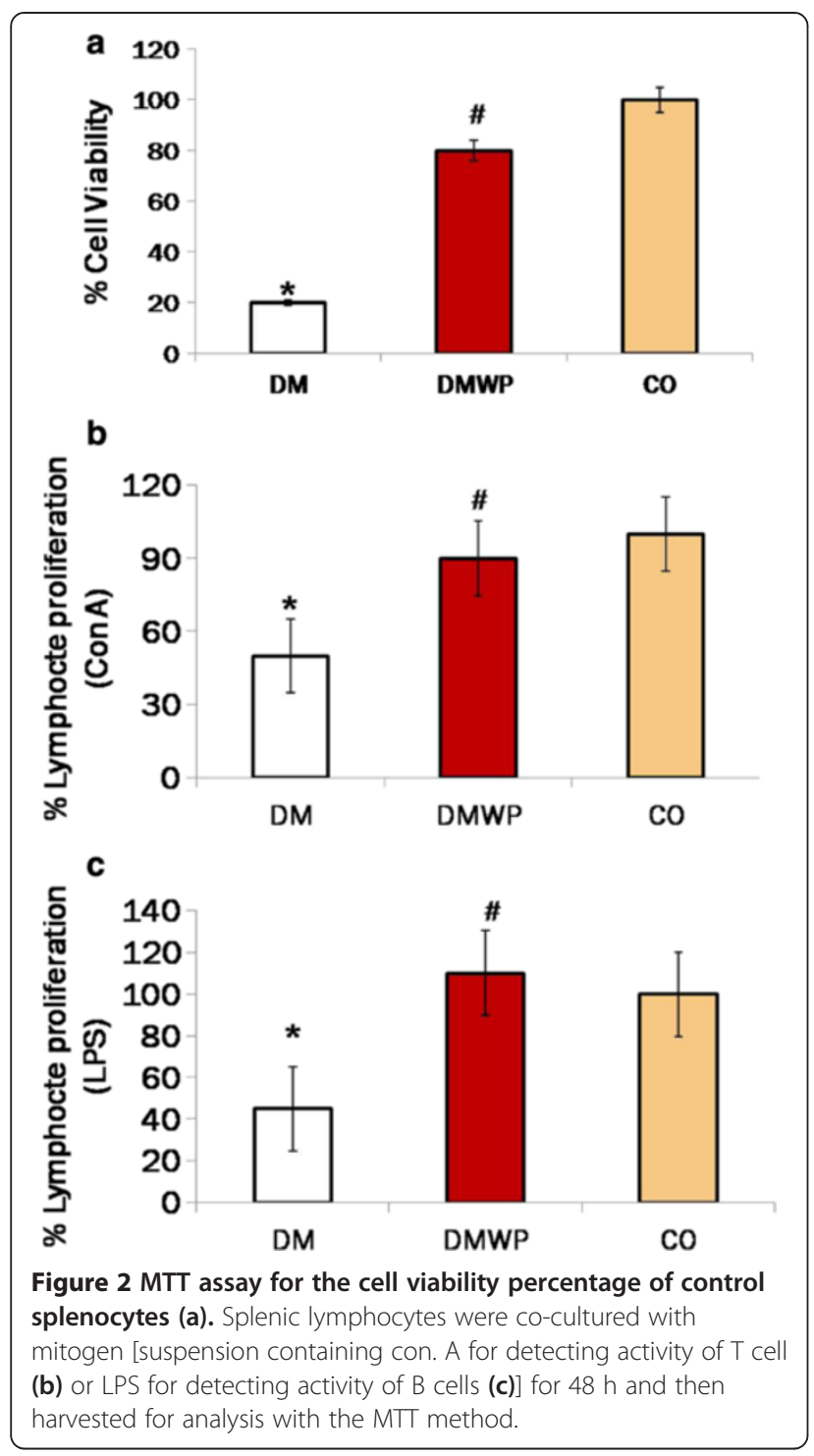

In addition, $\mathrm{T}$ cells, which destroy pancreatic $\beta$ cells, were extensively distributed in all zones, especially in the PALS, in the spleen sections of the diabetic rats (Figure $5 \mathrm{c}, \mathrm{d})(2.5$ fold compared to the control group). WP was found to significantly $(P<0.05)$ reduce these T cells $(20 \pm 3.1)$ one fifth and one half their number in the diabetic $(107 \pm 11)$ and control $(39 \pm 3.6)$ groups, respectively (Figure $5 \mathrm{~g}$ ).

\section{WP increases polyfunctional T cells and down regulates mRNA expression of TNF- $\alpha$ and Fas during diabetes}

After exploring the impact of WP on the proliferative activity of both $\mathrm{T}$ and $\mathrm{B}$ cells the polyfunctional activity of $\mathrm{T}$ cells was investigated by detecting the expression of two important cytokines, IFN- $\gamma$ and IL-2-mRNA. As shown in Figure $6 \mathrm{a}, \mathrm{b}, \mathrm{mRNA}$ expression of IFN- $\gamma$, which has a critical role in intracellular immune activity, was significantly $(P<0.05)$ impaired in the diabetic rats $[4$ (Figure 6a) and 2-fold (Figure 6b) reduced compared to the control group]. IFN $-\gamma$ concentration detected by ELISA showed similar behavior in diabetic group (Figure $6 \mathrm{c}$ ). IFN- $\gamma$ mRNA in diabetic rats supplemented with WP were significantly $(P<0.05) 3$-fold $(15 \pm 2.67)$ increased compared to the diabetic rats $(5.0 \pm 1.1)$ (Figure 6a).

In regard to the mRNA expression of IL-2, however, no significant difference was observed between the diabetic and control groups (Figure 6d) despite its protein level was significantly $(P<0.05)$ lowered (Figure 6e). Although WP minimized the number of $\mathrm{T}$ cells in the splenic tissues, WP was found to significantly restore the number of polyfunctional T cells (i.e. IFN- $\gamma$ and IL-2-producing cells). WP was found to significantly $(P<0.05)$ elevate the mRNA expression of IL-2 $(250 \pm 12.7)$ compared to the diabetic $(148 \pm 6.8)$ and control $(119 \pm 4.9)$ groups (Figure $6 \mathrm{~d}$ ).

To validate this data and to ascertain the impact of WP on the pancreatic $ß$-cell mass, we observed mRNA expression of TNF- $\alpha$ and one of its receptors (Fas), which, together with inflammatory cytokines, are the key factors in the destruction of $\beta$-cell mass in T1D. The mRNA expression of TNF- $\alpha$ was significantly increased in diabetic rats (309 \pm 14.55$)$ but, in contrast, WP treatment was found to normalize the mRNA expressions of this gene $(220 \pm 9.11)$ (Figure 6f). By ELISA, WP was found to significantly reduce TNF- $\alpha$ (Figure $6 \mathrm{~g}$ ). The mRNA expression of Fas was significantly increased in diabetic rats $(164 \pm 7.29)$ compared to the control group $(2.0 \pm 0.034)$ (Figure $6 \mathrm{~h}$ ).

\section{WP normalizes the structure and function of pancreatic B cells}

Furthermore, the histological structure of the pancreas from the three different groups was investigated to assess whether there were any observable impacts on the diabetic rates of supplementation with WP. While degenerative changes in the nuclei of the pancreatic $ß$-cells were observed in the microscopic sections of the untreated diabetic rats, with nuclei appearing darkly stained with fragmented chromatin (Figure 7b), in those animals treated with WP, more normal morphological features of the pancreatic ßcells were restored (Figure 7c).

An improvement in the pancreatic cell function was also found. WP supplementation improved glucose clearance, enabling the basal plasma glucose concentration in those diabetic animals treated with WP to be significantly $(P \leq$ $0.005)$ normalized to the concentration levels in the control animals (Figure 7d). This confirmed that insulin release from the pancreatic islets was restored to normal levels $(24 \pm 2.6)$ in diabetic rats supplemented with WP $(26 \pm 2.28)$ (Figure 7e).

\section{Discussion}

Inflammatory cytokines stimulate multiple signaling cascades leading to $ß$ cell apoptosis [13] in T1D [29]. By 


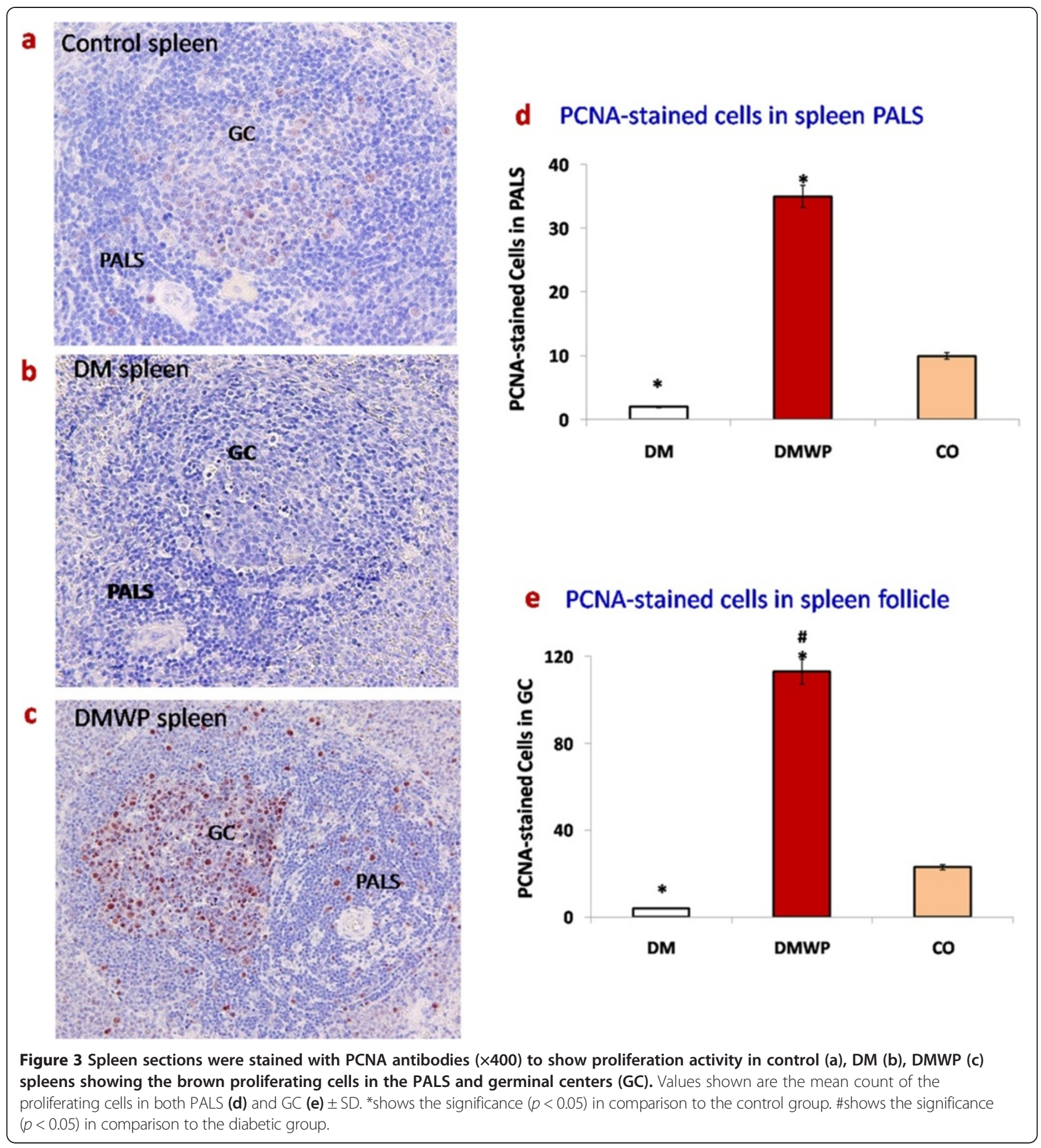

suppressing inflammatory cytokines, WP increases the capacity of diabetic $[15,17]$ animals to heal wounds. Potential effects of WP on immune processes, including the regulation of cytokines [30] and enhancement of the proliferation capability of PBMCs [16] have been observed. WP, therefore, can not only suppresses the inflammatory cytokines from autoreactive $\mathrm{T}$ cells but also restore normal $\beta$-cell mass and function during diabetes.
In this study diabetes was found significantly to impair the proliferative response of splenic lymphocytes in vivo and antigen-stimulated lymphocytes in vitro. Indeed, we did not observe any significant proliferation activities in the PALS zone, which are provoked by CD4+ T cells. Similarly, Aarnisalo et al. [31] found a marked reduction in the proliferative response of $\mathrm{CD} 4+\mathrm{T}$ cells among patients with T1D. 

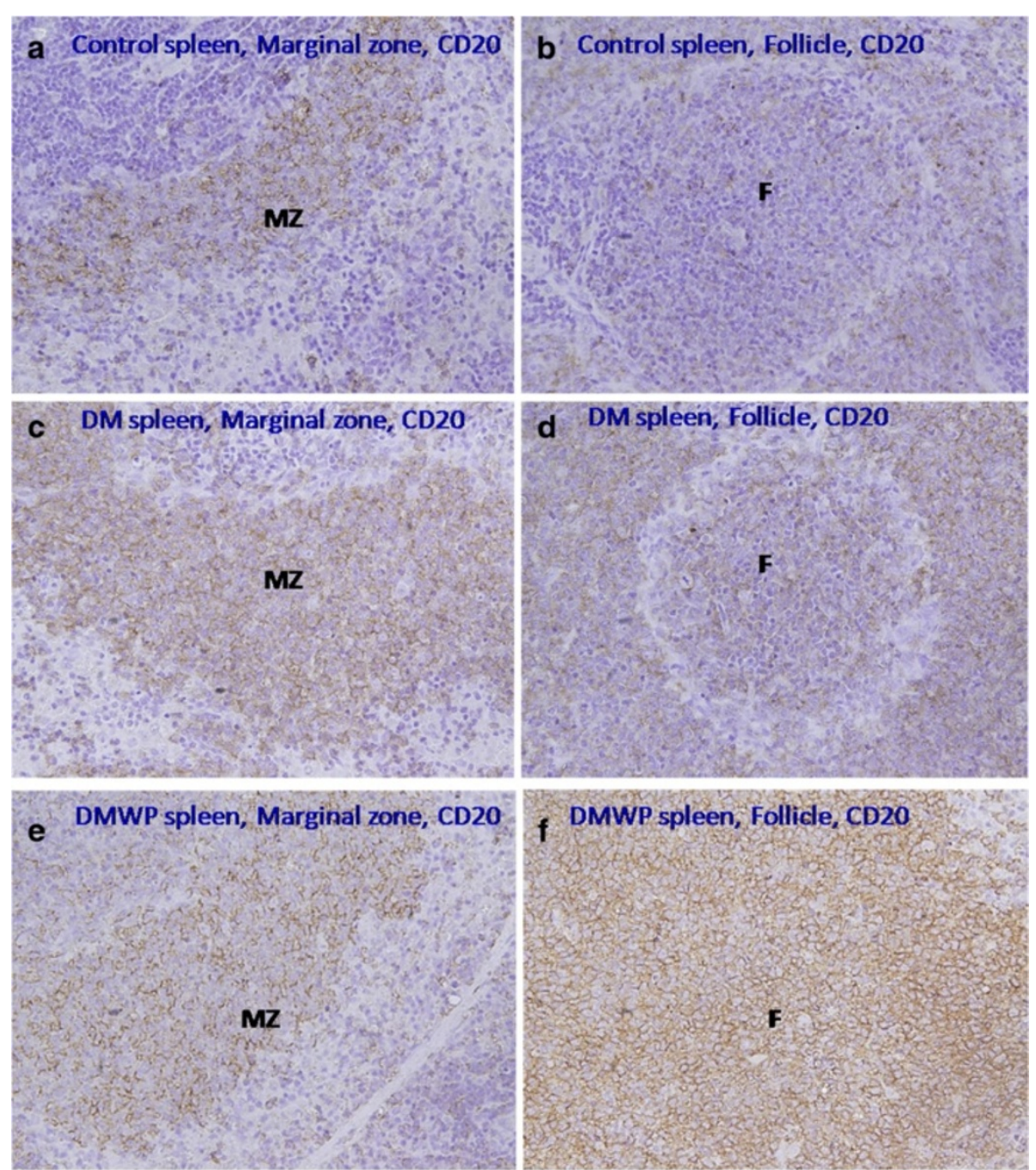

g CD20 stained cell count in spleen

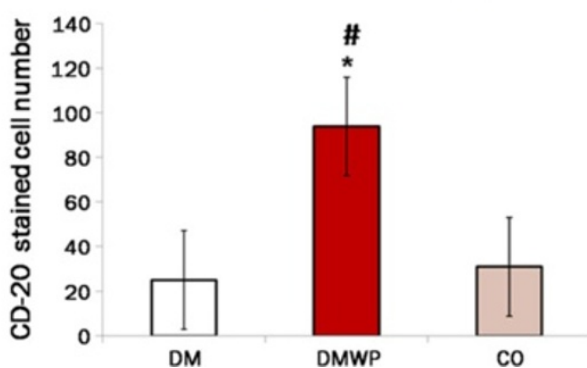

Figure 4 Spleen sections stained with anti-CD20+ antibodies to realize B cells. It shows the marginal zone and lymphatic follicles in the control $(\mathbf{a}, \mathbf{b}), \mathrm{DM}(\mathbf{c}, \mathbf{d})$ and DMWP $(\mathbf{e}, \mathbf{f})$ groups. The number of B cells was reduced in the marginal zone (MZ) and lymphatic follicles (F) of the diabetic rats and increased in both areas in WP treated diabetic rats $(\times 400)$. Values shown are the mean count of the CD-20 cells in both MZ and $F(\mathbf{g}) \pm S D$. *shows the significance $(p<0.05)$ in comparison to the control group.

It is evident from our results that, in WP-treated rats, lymphocytes in splenic follicles showed highly significant proliferating activity, and this was confirmed in vitro. Although WP activates cell proliferation, therefore, staining with anti-PCNA antibodies showed that this proliferation was located in the B cell zone but not in the T cell zone of the splenic tissue. The proliferation activity stimulated by WP, therefore, was directed toward B cells rather than $\mathrm{T}$ 

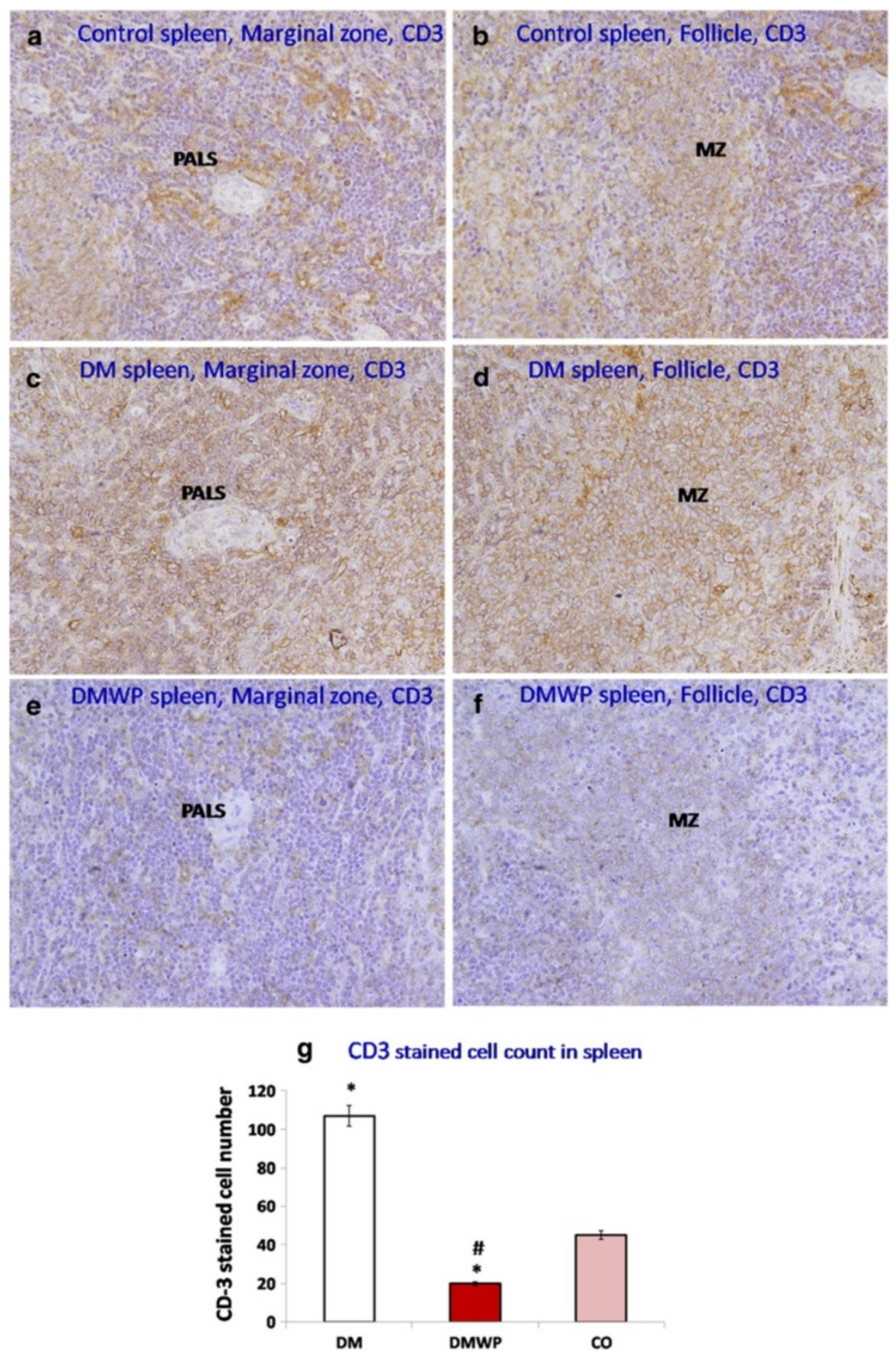

Figure 5 Spleen sections stained with anti-CD3+ antibodies to realize T cells. It shows the marginal zone and lymphatic follicles in the control $(\mathbf{a}, \mathbf{b}), \mathrm{DM}(\mathbf{c}, \mathbf{d})$ and DMWP $(\mathbf{e}, \mathbf{f})$ groups. T cells are strongly distributed in all zones, especially PALS, in the spleen sections of the diabetic rats. Interestingly, WP greatly reduced the number of T cells in the tissues of diabetic rats $(\times 400)$. Values shown are the mean count of the CD-3+ cells in both MZ and F $(\mathbf{g}) \pm S D$. * shows the significance $(p<0.05)$ in comparison to the control group.

cells. This finding was confirmed by staining with antiCD20+ and anti-CD3+ antibodies which demonstrated that the number of $\mathrm{B}$ cells was greatly increased but that the number of $\mathrm{T}$ cells was reduced in the tissues of the WPtreated diabetic rats compared with untreated diabetic rats.
This provides further evidence that WP is associated with B cell stimulation and $\mathrm{T}$ cell suppression during diabetes.

Our results suggest that WP may suppress the Th1 type of $\mathrm{T}$ cell that has a critical role in diabetic complications. This suggestion was practically confirmed by the 
a

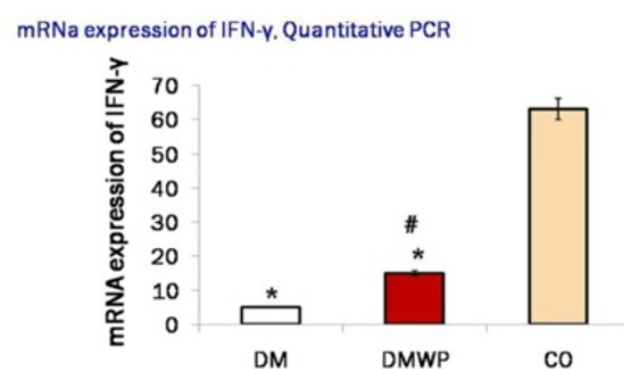

b

mRNa expression of IFN-y. RT-PCR

M DM DMWP CO
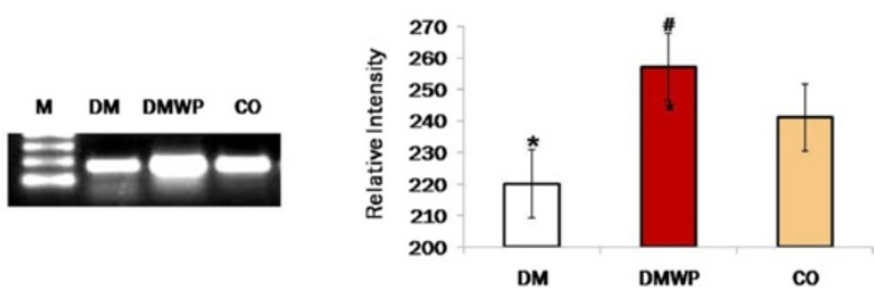

d mRNa expression of IL-2, RT-PCR
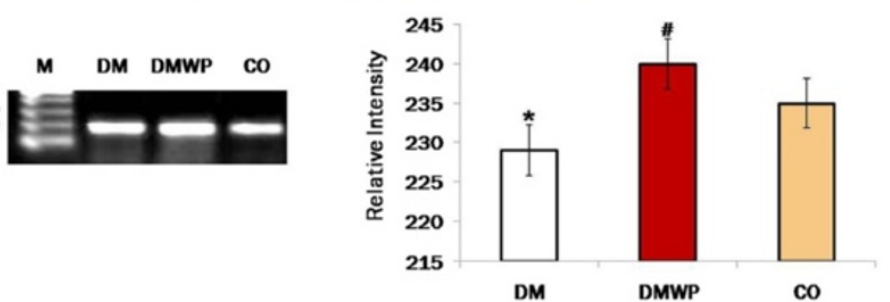

f

mRNa expression of TNF- $\alpha$, RT-PCR

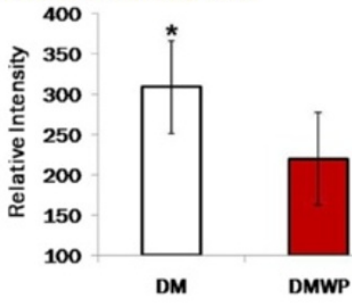

M DM DMWP CO

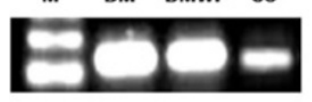

M DM DMWP co

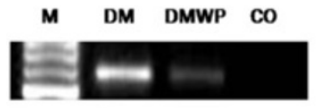

h mRNa expression of Fas, RT-PCR

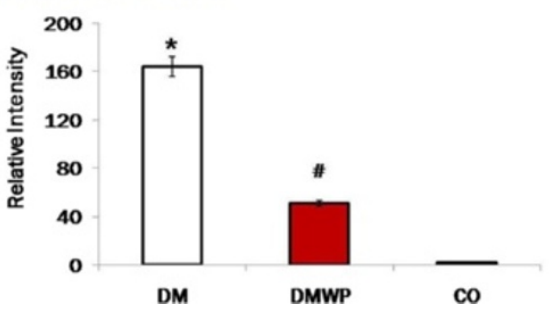

Figure 6 Quantitative analysis of mRNA expression of AKT1 genes (a). Semiquantative PCR-mRNA expression and the supernatant levels of IFN- $\gamma(\mathbf{b}, \mathbf{c})$ and IL-2 (d, e). It was found that WP restores the polyfunctional T cells (IFN- $\gamma$ and IL-2 producing cells that exhibit a high proliferation capacity). The mRNA expressions (f) and the supernatant level (g) of TNF-a, and the mRNA expressions of Fas (h). Samples from five animals were analyzed. Samples from five animals were analyzed, while a representative result from each group is presented in this figure. Values shown are mean values \pm SD. * shows the significance $(p<0.05)$ in comparison to the control group. \#shows the significance $(p<0.05)$ in comparison to the diabetic group. 

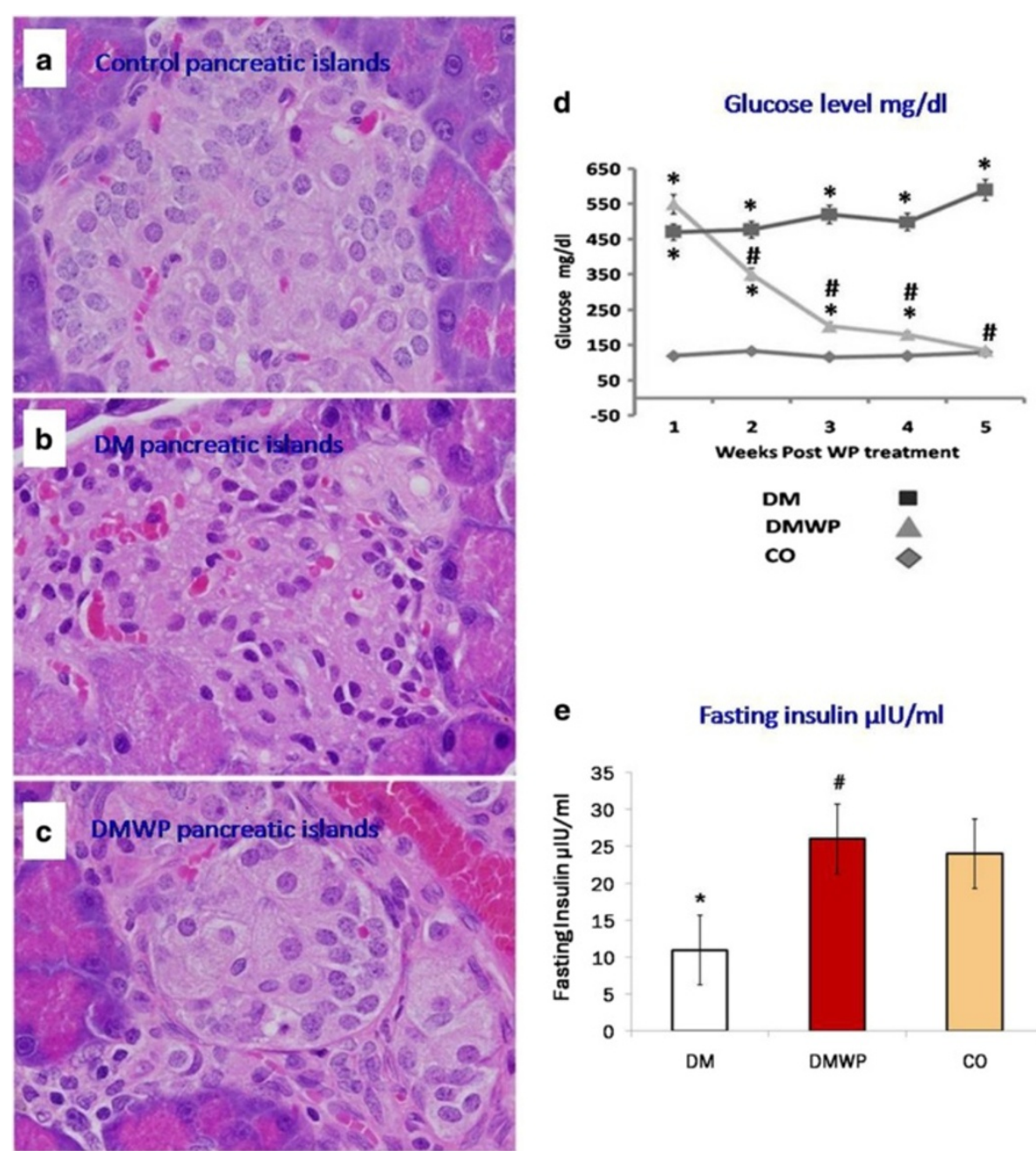

e

Fasting insulin $\mu \mathrm{lU} / \mathrm{ml}$

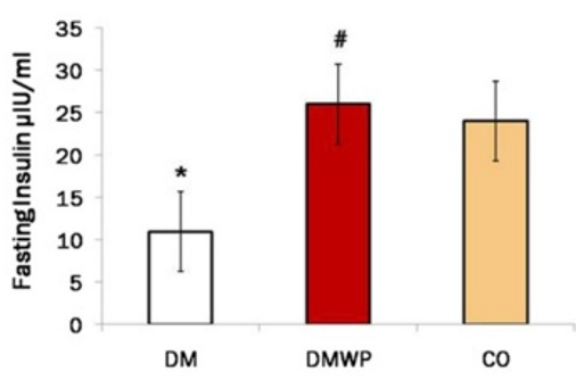

Figure 7 Representative microscopic sections of the control (a), DM (b) and DMWP (c) rats (E\&H $\times 400)$. Plasma glucose (d) and insulin (e) concentration of the control, DM and DMWP rats. ${ }^{*}$ shows the significance $(p<0.05)$ in comparison to the control group. \#shows the significance $(p<0.05)$ in comparison to the diabetic group.

up-regulation of Cdc42 expression, which maintains the homeostasis of naïve $\mathrm{T}$ cells by promoting cell survival and suppressing $\mathrm{T}$ cell activation [12]. Cdc42-deficient naive $\mathrm{T}$ cells display impaired actin polymerization and show an enhanced differentiation to Th1 and CD8+ effector and memory cells [12]. Restoring Cdc42 by WP may, therefore, maintain the balance between the Th1 and Th2 subsets of $\mathrm{T}$ cell by specifically suppressing $\mathrm{T}$ cell activation and differentiation to Th1 and $\mathrm{CD}^{+}$effector and memory cells. Ultimately, this T cell homeostasis results in an improvement in the condition of the pancreatic $ß$ cells.

Akt is critical for cell survival and is triggered by different stimuli [32]. WP supplementation was found to restore mRNA expression of Akt1 to the normal level. It was also shown in this work that up-regulation of Akt1 was accompanied by a significant increase of lymphocyte proliferation in the splenic tissues. The mRNA expression of the activated lymphocytes showed that diabetes had decreased the Akt1 signaling. Inhibition of cell migration has also been shown to be effected by inhibition of phosphorated PI3K/Akt, resulting in rapid Cdc42 proteolysis [33]. These studies confirm that Akt depletion impairs the mRNA expression of Cdc42 by activated lymphocytes during diabetes. Taken together, the results of our study confirm that WP linked up-regulation of Akt1 significantly elevates $\mathrm{Cdc} 42$ and this enhances $\mathrm{T}$ cell homeostasis but not $B$ cells attacking Th1 cells.

Cell death stimuli signals are either an intrinsic, mitochondrial pathway of apoptosis or can kill the cell through one of the six death receptors such as Fas [1]. Fas was significantly up-regulated in diabetic rats, as shown by the high number of dead lymphocytes in the diabetic group, suggesting that diabetic complications 
and oxidative stress induce cell apoptosis via Fas upregulation [34,35]. The increased expression of Fas in the diabetic lymphocytes was, however, significantly inhibited by WP treatment. This indicates that WP restored $\mathrm{T}$ cell homeostasis by suppressing $\mathrm{T}$ cell proliferating activity rather than through the Fas-mediated apoptotic pathway.

Turning now to CD28, we found a lower level of CD28 expression on antigen-stimulated lymphocytes in the diabetic group while this level was restored in diabetic rats treated with WP. Recent studies have demonstrated that a significantly lower level of CD28 surface expression on T cells was detected in diabetic rats, children with T1D, cell leukaemia, chronic lymphocytic leukaemia and colorectal cancer [36-38]. CD28 may contribute to T cell viability by increasing glucose metabolism in activated $\mathrm{T}$ cells [39]. CD28 signals are also required to protect T cells from Fasmediated apoptosis by activating the PI3K/Akt pathway [40]. Thus, a lower level of CD28 surface expression on T cells from diabetic rats could explain the observed twofold higher level of dead cells in the diabetic group. In the absence of co-stimulation, cytokine secretion and $\mathrm{T}$ cell expansion, proliferation, survival and memory development are affected $[41,42]$. The diabetic rats in our study also exhibited decreased IL-2 or IFN- $\gamma$ expression, which is a major $\mathrm{T}$ cell function. On the other hand, it is likely that the higher level of CD28 surface expression in the WP-treated animals causes the higher viability and proliferating capacity, and the restoration of IL- 2 and IFN- $\gamma$ levels.

WP suppresses TNF- $\alpha$ production, which is the key factor in $\beta$ cell-destruction in T1D since TNF- $\alpha$ controls the expression of the inflammatory gene network and contributes to the pathological complications observed in many inflammatory diseases such as schizophrenia and diabetes $[43,44]$. Therefore, while the higher expression of TNF- $\alpha$ caused pancreatic damage and dysfunction in the diabetic group in this study, WP was found to regulate expression of TNF- $\alpha$ and its apoptosis receptor, Fas to normal levels. By increasing glutathione, WP also induces oxidative stability leading to suppression of the inflammatory cascade [15]. Since blocking the production of TNF- $\alpha$ improves blood glucose concentrations, targeting TNF- $\alpha$ could effectively reduce expressions of the primary factors behind the complications associated with diabetes [45]. Thus, normal morphological features of the pancreatic ß-cells and glucose clearance were restored in the diabetic rats treated with WP due to the suppression of TNF- $\alpha$. The hypoglycaemic effect of WP in individuals with T1D has recently been confirmed [46,47] and WP has also been shown to restore the capacity of the pancreatic islet to secrete insulin [48]. Here, we add to this picture of the beneficial effects of WP in the context of diabetes by showing that WP supplementation for five weeks in normalized glucose clearance in diabetic rats.

In conclusion, we have shown here that there is a strong, positive correlation between WP and immune function during diabetes in an animal model. WP restored the normal immune response as follows: 1) by activating the Akt1 pathway, it activated the CD28 signals required to protect $\mathrm{T}$ cells from Fas-mediated apoptosis; 2) by stimulating $\mathrm{Cdc} 42$, which maintains naïve $\mathrm{T}$ cell homeostasis by promoting cell survival and suppressing $\mathrm{T}$ cell activation. This leads to the restoration of the polyfunctional T cells (IFN- $\gamma$ and IL-2 production), increased cell viability, and may restore the $\mathrm{T}$ cell subset balance; 3 ) by suppressing TNF- $\alpha$ and its receptor, Fas. The positive outcome of this range of effects at the cellular level are confirmed by our evidence on improvements of the pancreatic $ß$ cell mass and function. There is a need, however, to investigate more intensively the potential role of WP in the treatment of diabetic immune impairment.

\section{Abbreviations}

Cdc42: Cell division control protein 42; MTT: Cell proliferation assay; CD28: Co-stimulatory molecule; H\&E: Haematoxylin-eosin; (IL)-2: Interleukin; IFN-ץ: Interferon gamma; Fas: Programmed cell death-receptor;

PBMC: Peripheral blood mononuclear cells; PCNA: Proliferated cell nuclear antigen; Akt1: Protein kinase B; TCR: T cell receptor; STZ: Streptozotocin; TNF-a: Tumour necrosis factor-alpha; T1D: Type 1 diabetes; WP: Whey protein.

\section{Competing interests}

The author declares that there to be no competing interests.

\section{Acknowledgement}

This project was supported by King Saud University, Deanship of Scientific Research, College of Science Research Centre.

Received: 10 May 2014 Accepted: 25 June 2014

Published: 1 July 2014

\section{References}

1. Baumler C, Kim GO, Elkon KB: Growth regulation of activated lymphocytes: defects in homeostasis lead to autoimmunity and/or lymphoma. Rev Immunogenet 2000, 2:283-290.

2. Vergani $D$, Mieli-Vergani $G$ : Aetiopathogenesis of autoimmune hepatitis. World J Gastroenterol 2008, 14:3306-3312.

3. Zouidi F, Stayoussef M, Bouzid D, Fourati H, Abida O, Ayed MB, Kammoun T, Hachicha M, Penha-Gonçalves C, Masmoudi H: Contribution of PTPN22, CD28, CTLA-4 and ZAP-70 variants to the risk of type 1 diabetes in Tunisians. Gene 2013, 1119:1346-1352.

4. Kane LP, Andres PG, Howland KC, Abbas AK, Weiss A: Akt provides the CD28 costimulatory signal for up-regulation of IL-2 and IFN-gamma but not TH2 cytokines. Nat Immunol 2001, 2:37-44.

5. Sugden $\mathrm{PH}$, Clerk A: Akt like a woman: gender differences in susceptibility to cardiovascular disease. Circ Res 2001, 88:975-977.

6. Hers I, Vincent EE, Tavare JM: Akt signaling in health and disease. Cell Signal 2011, 10:1515-1527.

7. Beveren NJ, Krab LC, Swagemakers S, Buitendijk GH, Boot E, van der Spek $P$, Elgersma $Y$, van Amelsvoort TA: Functional gene-expression analysis shows involvement of schizophrenia-relevant pathways in patients with 22q11 deletion syndrome. PLoS One 2012, 7:e33473.

8. Etienne-Manneville S, Hall A: Rho GTPases in cell biology. Nat Geosci 2002 420:629-635.

9. Itoh RE, Kurokawa K, Ohba Y, Yoshizaki H, Mochizuki N, Matsuda M: Activation of rac and cdc42 video imaged by fluorescent resonance 
energy transfer-based single-molecule probes in the membrane of living cells. Mol Cell Biol 2002, 22:6582-6591.

10. Ni S, Hu J, Duan Y, Shi S, Li R, Wu H, Qu Y, Li Y: Down expression of LRP1B promotes cell migration via RhoA/Cdc42 pathway and actin cytoskeleton remodeling in renal cell cancer. Cancer Sci 2013, 104:817-825

11. Runne C, Chen S: PLEKHG2 promotes heterotrimeric $G$ protein $\beta \gamma$-stimulated lymphocyte migration via Rac and Cdc42 activation and actin polymerization. Mol Cell Biol 2013, 33(21):4294-4307.

12. Go MJ: Activation of Rac1 or Cdc42 during early morphogenesis of eye discs induces ectopic antennae in Drosophila. Dev Growth Differ 2005, 47:225-231

13. Faloon PW, Chou DHC, Forbeck EM, Walpita D, Morgan B, Buhrlage S, Ting A, Perez J, MacPherson LJ, Duvall JR, Dandapani S, Marcaurelle LA, Munoz B, Palmer M, Foley M, Wagner B, Schreiber SL: Identification of Small Molecule Inhibitors that Suppress Cytokine-Induced Apoptosis in Human Pancreatic Islet Cells. Probe Reports from the NIH MolecularLibraries Program [Internet]. Bethesda (MD): National Center Biotechnology Information (US); 2011.

14. Dempsey PW, Doyle SE, He JQ, Cheng G: The signaling adaptors and pathways activated by TNF superfamily. Cytokine Growth Factor Rev 2003 14:193-209.

15. Ebaid H, Salem A, Sayed A, Metwalli A: Whey protein enhances normal inflammatory responses during cutaneous wound healing in diabetic rats. Lipids Health Dis 2011, 10:235.

16. Badr G, Ebaid H, Mohany H, Abuelsaad AS: Modulation of immune cell proliferation and chemotaxis towards CC chemokine ligands (CCL)-21 and $C X C$ chemokine ligand $(C X C L)-12$ in un-denatured whey protein-treated mice. J NutritBiochem 2011, 23:1640-1646.

17. Ebaid $\mathrm{H}$, Ahmed $\mathrm{O}$, Mahmoud A, Ahmed R: Limiting prolonged inflammation during proliferation and remodeling phases of wound healing in streptozotocin-induced diabetic rats supplemented with camel undenatured whey protein. BMC Immunol 2013, 14:31.

18. Ebaid $\mathrm{H}$ : Neutrophil depletion in the early inflammatory phase delayed cutaneous wound healing in older rats: improvements due to the use of un-denatured camel whey protein. Diagnostic Pathol 2014, 4(9(1)):46.

19. Li Z, Zhang T, Dai H, Liu G, Wang H, Sun Y, Zhang Y, Ge Z: Involvement of endoplasmic reticulum stress in myocardial apoptosis of streptozocin-induced diabetic rats. J Clin Biochem Nutr 2007, 41:58-67.

20. Bounous G, Gervais F, Amer V, Batist G, Gold P: The influence of dietary whey protein on tissue glutathione and the diseases of aging. Clin Invest Med 1989, 12:343-349.

21. Bounous G, Kongshavn PA, Taveroff A, Gold P: Evolutionary traits in human milk proteins. Med Hypotheses 1988, 27:133-140.

22. Moura C, Lollo P, Morato P, Nisishima L, Carneiro E, Farfa J: Whey Protein Hydrolysate Enhances HSP90 but Does Not Alter HSP60 and HSP25 in Skeletal Muscle of Rats. PLoS One 2014, 9:e83437.

23. Ebaid $H$, Hassanein KA, El-Feki MA: The undenatured whey protein enhanced wound healing in mice. J Egyp Germ Society Zool 2005, 47:267-287.

24. Trinder P: Determination of blood glucose using 4-amino phenazone as oxygen acceptor. J Clim Appl Meteorol 1969, 22:246.

25. Marschner I, Bottermann P, Erhardt F, Linke R, Maier V, Schwandt P: Group experiments on the radio-immunological insulin determination. Hormone Metabol Res 1974, 6:293-296.

26. Sylvester PW: Optimization of the tetrazolium dye (MTT) colorimetric assay for cellular growth and viability. Methods Mol Bio/ 2011, 716:157-168.

27. She Y, Chen NW, Zhu Y, Xia S, Hu C, Li Y: Effects of Aluminum on Immune Functions of Cultured Splenic T and B Lymphocytes in Rats. Biol Trace Elem Res 2012, 147:246-250.

28. Kazi M, Thyberg J, Religa P, Roy J, Eriksson P, Hedin U, Swedenborg J: Influence of intraluminal thrombus on structural and cellular composition of abdominal aortic aneurysm wall. J Vasc Surg 2003, 38:1283-1292.

29. Zhang T, Guo P, Zhang Y, Xiong H, Yu X, Xu S, Wang X, He D, Jin X: The antidiabetic drug metformin inhibits the proliferation of bladder cancer cells in vitro and in vivo. Int J Mol Sci 2013, 18:24603-24618.

30. Ebaid H, Badr G, Metwalli A: Immunoenhancing property of dietary un-denatured whey protein derived from three camel breeds. Biologia 2012, 67:425-433.

31. Aarnisalo J, Treszl A, Svec P, Marttila J, Oling V, Simell O, Knip M, Körner A, Madacsy L, Vasarhelyi B, llonen J, Hermann R: Reduced CD4 + T cell activation in children with type 1 diabetes carrying the PTPN22/Lyp 620Trp variant. J Autoimmun 2008, 31:13-21.

32. Engedal $\mathrm{N}$ : Immune regulator vitamin $\mathrm{A}$ and $\mathrm{T}$ cell death. Vitam Horm 2011, 86:153-178.

33. Cheng WY, Chiao MT, Liang YJ, Yang YC, Shen CC, Yang CY: Luteolin inhibits migration of human glioblastoma U-87 MG and T98G cells through downregulation of Cdc42 expression and PI3K/AKT activity. Mol Biol Rep 2013, 40:5315-5326.

34. Sainio-Pollanen S, Erkkila S, Alanko S, Hanninen A, Pollanen P, Simell O: The role of Fas ligand in the development of insulitis in nonobese diabetic mice. Pancreas 1998, 16:154-159.

35. Park GB, Kim YS, Lee HK, Cho DH, Kim D, Hur DY: CD80 (B7.1) and CD86 (B7.2) induce EBV-transformed B cell apoptosis through the Fas/FasL pathway. Int J Oncol 2013, 43:1531-1540.

36. Na S, Li B, Grewal IS, Enslen H, Davis R, Hanke JH, Flavell RA: Expression of activated CDC42 induces $T$ cell apoptosis in thymus and peripheral lymph organs via diferent pathways. Oncogene 1999, 18:7966-7974.

37. Badr G, Bashandy S, Ebaid H, Mohany M, Sayed D: Vitamin C supplementation reconstitutes polyfunctional T cells in streptozotocin-induced diabetic rats. Eur J Nutr 2012, 51:623-633.

38. Pawłowski $P$, Urban M, Stasiak-Barmuta A: Surface expression of costimulatory molecules CD28/CTLA-4 on peripheral blood T lymphocytes in the course of type 1 diabetes mellitus in children and adolescents. Endokrynol Diabetol Chor Przemiany Materii Wieku Rozw 2004, 10:81-85.

39. Frauwirth KA, Riley JL, Harris MH, Parry RV, Rathmell JC, Plas DR, Elstrom RL, June $\mathrm{CH}$, Thompson CB: The CD28 signaling pathway regulates glucose metabolism. Immunity 2002, 16:769-777.

40. Jones RG, Elford AR, Parsons MJ, Wu L, Krawczyk CM, Yeh WC, Hakem $R$, Rottapel R, Woodgett JR, Ohashi PS: CD28-dependent activation of protein kinase B/Akt blocks Fas-mediated apoptosis by preventing death-inducing signaling complex assembly. J Exp Med 2002, 5:335-348.

41. Fuse S, Zhang W, Usherwood EJ: Control of memory CD8+ T cell differentiation by CD80/CD86-CD28 costimulation and restoration by IL-2 during the recall response. J Immunol 2008, 180:1148-1157.

42. Ford ML, Koehn BH, Wagener ME, Jiang W, Gangappa S, Pearson TC, Larsen CP: Antigen-specific precursor frequency impacts T cell proliferation, differentiation, and requirement for costimulation. J Exp Med 2007, 204:299-309.

43. Kowalski J, Blada P, Kucia K, Madej A, Herman Z: Neuroleptics normalize increased release of interleukin- 1 beta and tumor necrosis factoralpha from monocytes in schizophrenia. Schizophr Res 2001, 50:169-175.

44. Nagata S: Apoptosis by death factor. Cell 1997, 8:355-365.

45. Tuorkeya MJ, Kamela KK, Zidan AA: Active Immunization Against Tumor Necrosis Factor-alpha Decreases Proinflammatory Cytokines, Oxidative Stress Mediators and Adhesion Molecules Risk Factors in Streptozotocin-induced Diabetic Rats. Endocr Metab Immune Disord Drug Targets 2013, 10:29-33.

46. Mortensen LS, Hartvigsen ML, Brader L, Astrup A, Schrezenmeir J, Holst JJ, Thomsen C, Hermansen K: Differential effects of protein quality on postprandial lipemia in response to a fat-rich meal in type 2 diabetes: comparison of whey, casein, gluten, and cod protein. Am J Clin Nutr 2009, 90:41-48.

47. Lan-Pidhainy $X$, Wolever TM: The hypoglycemic effect of fat and protein is not attenuated by insulin resistance. Am J Clin Nutr 2010, 91:98-105.

48. Gaudel C, Nongonierma AB, Maher S, Flynn S, Krause M, Murray BA, Kelly PM, Baird AW, FitzGerald RJ, Newsholme P: Whey protein hydrolysate promotes insulinotropic activity in a clonal pancreatic $\beta$-cell line and enhances glycemic function in ob/ob mice. J Nutr 2013, 143:1109-1114.

doi:10.1186/1743-7075-11-31

Cite this article as: Ebaid: Promotion of immune and glycaemic functions in streptozotocin-induced diabetic rats treated with un-denatured camel milk whey proteins. Nutrition \& Metabolism 2014 11:31 